\title{
Path to Perdition: Lessons Learnt from Inadequate Fixation of an L5 Fracture
}

\author{
Prasad Krishnan ${ }^{1, \odot}$ \\ ${ }^{1}$ Department of Neurosurgery, National Neurosciences Centre, \\ Kolkata, West Bengal, India
}

Indian J Neurotrauma:2021;18:88-90

\author{
Address for correspondence Prasad Krishnan, MS, MCh, National \\ Neurosciences Centre, Peerless Hospital Campus, 2nd Floor, \\ 360 Panchasayar, Kolkata 700094, West Bengal, India \\ (e-mail: prasad.krishnan@rediffmail.com).
}

\begin{abstract}
Keywords

- cauda equina syndrome

- implant failure

- lumbar fracture

- pediatric spine

- pedicle screws

- spinal injury

Pedicle screw fixation is a commonly performed operation following fractures of dorsal and lumbar spines. As neurosurgeons, our primary aim is decompression of neural structures and stabilization of the vertebral column. However, careful preoperative planning is imperative to restore the alignment of the spine in sagittal and coronal planes as otherwise implant failure and progressive deformity may result. Eleven years ago, I had operated on a 12-year-old child with an L5 fracture and cauda equina syndrome where no attempt was made to either do a corpectomy and reconstruct the body or reduce it by placing screws in the fractured segment or include additional levels in the construct. Over time he had only minimal improvement in neurological status. Unfortunately, there was sequential implant failure that led to eventual removal. The serial roentgenography in this case is described.
\end{abstract}

A 12-year-old boy had L5 fracture and posterior dislocation over S1 following a road traffic accident 11 years ago. He was unable to move both lower limbs below the knees and had loss of sphincter function. He underwent L4 to S1 fixation with L5 and S1 laminectomy to stabilize his spine and relieve compression on the thecal sac with the hope of improvement in neurological function. Intertransverse bone grafting was done. No attempt was made to reduce $\mathrm{L} 5$ in position, include it in the construct or remove it, and place a graft between L4 and S1 to reconstitute the anterior column of the spine. Over time he had some recovery in motor power in the lower limbs but could not ambulate independently and had no return of continence.

Serial X-rays showed progressive resorption of the L5 vertebral body and later breakage of the inferior pedicle screws at their necks and still later backout of the upper screws as well (-Fig. 1). Eventually, after 9 years the patient started experiencing a clicking sound and mild pain on sitting as well as a prominence underneath his skin. The implant was removed-except for the broken shaft of the S1 screws that were buried in the body of S1 (-Fig. 2)-to prevent skin erosion but the family refused to consent to a refixation with augmentation of the anterior column.

Pedicle screw and rod constructs provide excellent fixation in unstable thoracic and lumbar spinal injuries. However, over time, weight transmission depends not only on the construct but also on the integrity of the anterior and middle columns of the spine as the most of axial forces are transmitted through the vertebral bodies and discs. ${ }^{1}$ In the absence of anterior and middle column support (as in our case), increased tensile forces are placed on the posterior implants ${ }^{1}$ leading to implant failure. McCormack et $\mathrm{al}^{2}$ described a load sharing classification for spine fractures based on the extent of comminution, dislocation, and degree of kyphosis correction for predicting patients with higher chance of pedicle screw breakage who would be candidates for augmentation of the anterior column as well. Circumferential fixation followed next by posterior fixation with anterior strut grafting have shown superiority to posterior fixation alone in experimental models. ${ }^{3}$

In our case, anterior corpectomy at L5 would have been technically demanding and further it is difficult to published online September 29, 2020
DOI https://doi.org/

10.1055/s-0040-1714176

ISSN 0973-0508.
C)2020. Neurotrauma Society of India.

This is an open access article published by Thieme under the terms of the Creative Commons Attribution-NonDerivative-NonCommercial-License, permitting copying and reproduction so long as the original work is given appropriate credit. Contents may not be used for commercial purposes, or adapted, remixed, transformed or built upon. (https://creativecommons.org/licenses/by-nc-nd/4.0/). Thieme Medical and Scientific Publishers Pvt. Ltd. A-12, 2nd Floor, Sector 2, Noida-201301 UP, India 


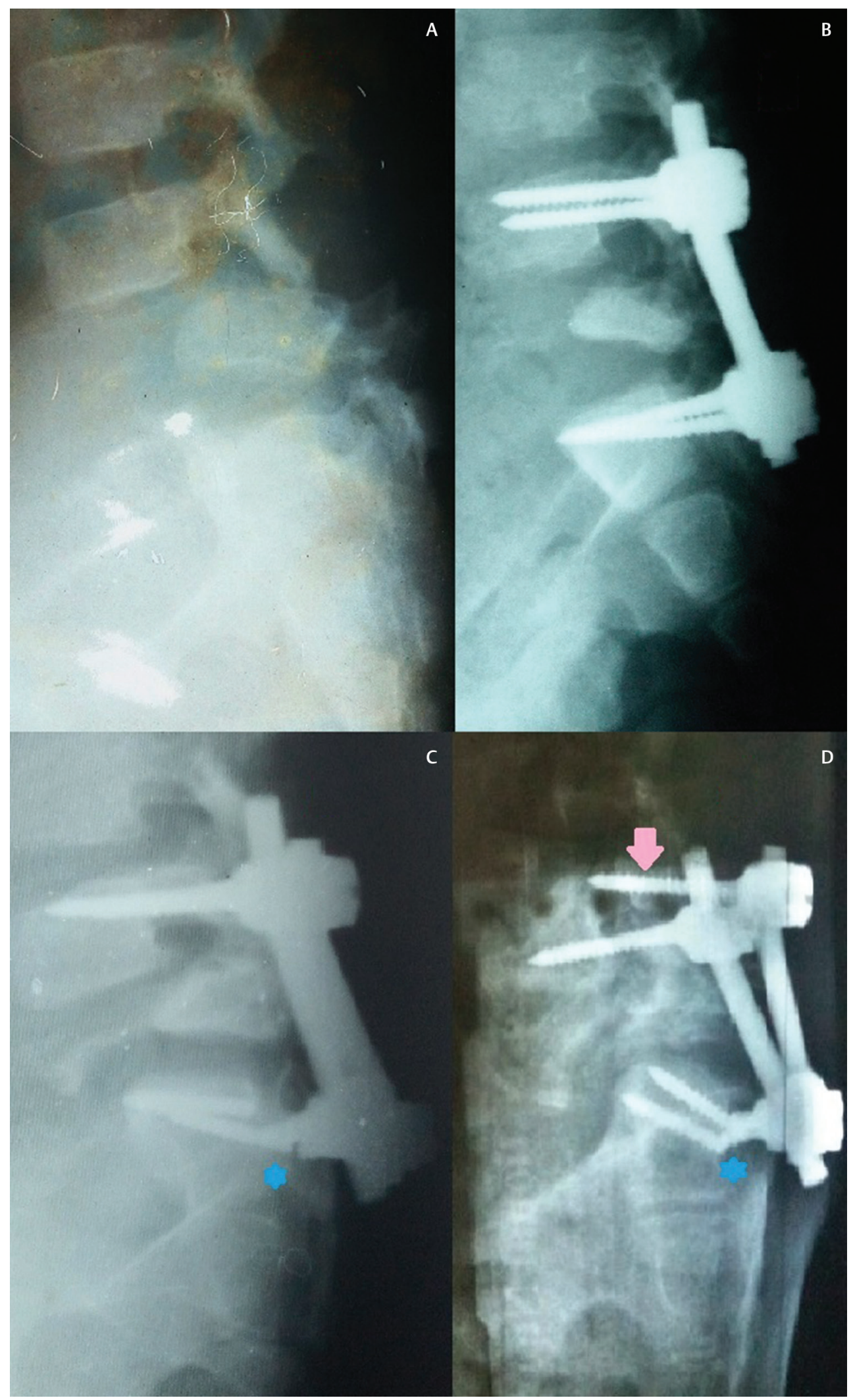

Fig. 1 Lateral X-rays showing (A) fracture of L5 with anterior dislocation of L4 on L5 and retrolisthesis of L5 on S1; (B) postoperative image after 1 year showing resorption of L5 with fixation of L4 on S1; (C) imaging after 5 years showing fracture of S1 pedicle screws bilaterally (blue star); and (D) imaging after 9 years showing backout of screws from L4 vertebral body (pink arrow). 


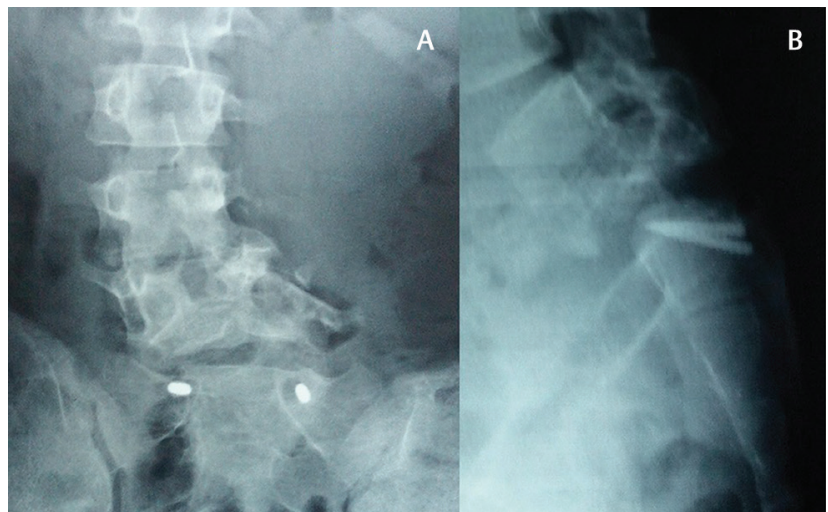

Fig. 2 Postoperative $X$-rays after1 year after implant removal (A) anteroposterior (AP) and (B) lateral views showing almost complete resorption of L5 body with residual pedicle screw shaft remaining in body of $\mathrm{S} 1$ vertebra.

incorporate S1 into an anterior construct. Other strategies that could have been used are adding screws into the affected level which has been shown to improve stability and maintain kyphosis correction ${ }^{1}$ as well as long segment fixation. In 37 operated cases of thoracolumbar junctional fractures (all posterior fixations), we reported 2 cases of screw backout-both occurring in short segment fixations and have recommended including additional segments to improve stability. ${ }^{4}$ Retrospectively, we feel we could have placed iliac screws and could have also included L3 in the construct or put screws in L5 and tried to reduce the dorsal displacement.

Careful thought must be given to complex fractures in junctional areas of the spine and optimum surgical planning should aim for not only neural decompression in the short term but also good spinal alignment and ensuring stability of the implant in the long run.

\section{Funding}

None.

\section{Conflict of Interest}

None declared.

\section{References}

1 Bronson WH, Vaccaro AR. Is there a role for anterior augmentation in thoracolumbar burst fractures? Indian Spine J 2018;1:86-93

2 McCormack T, Karaikovic E, Gaines RW. The load sharing classification of spine fractures. Spine 1994;19(15):1741-1744

3 Kallemeier PM, Beaubien BP, Buttermann GR, Polga DJ, Wood KB. In vitro analysis of anterior and posterior fixation in an experimental unstable burst fracture model. J Spinal Disord Tech 2008;21(3):216-224

4 Krishnan P, Kartikueyan R, Patel SM, Deb S. Pedicle screw loosening - reassessing short segment fixation in dorsolumbar junctional fractures. Neurol India 2017;65(2):382-385 